
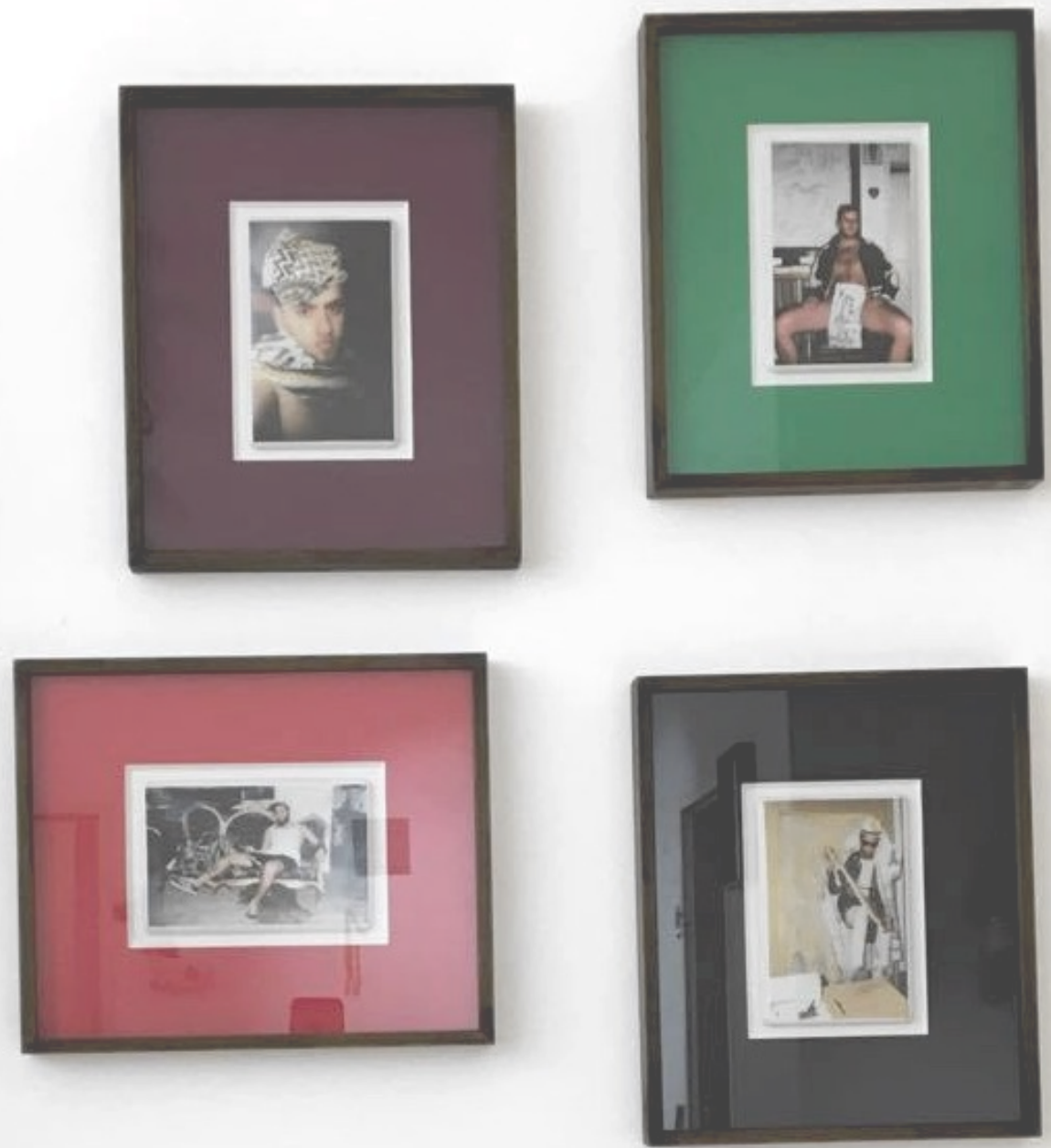

Photoceramics,'Pipe', 'Evereft', 'Taner' and 'No Title' from 2015 by Bernhard Rappold; essay by Elisabeth Bene.

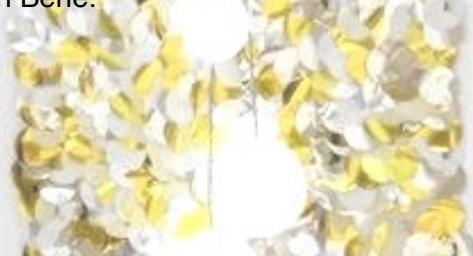




\section{On Regimes of Value in the Art World and the Art of Bernhard Rappold}

\section{Elisabeth Bene}

Fine art may be the most subjective commodity of all, something that makes the value of art subjective as well. Accordingly, many factors influence the creation of value in an artist's work beyond the cost of materials and the time it took to create. An artist's inclusion in an important gallery or a museum show, or inclusion in the collections of influential and respected collectors can have a positive impact on the price. Furthermore, there are more complex factors to consider. But what factors are decisive for the valorisation of an art work? What is the artist's significance in the context of art history? What roles do the processes of modernity and modernization play in these contexts?

The following essay aims to discuss these questions using the example of the Viennese artist Bernhard Rappold, within a theoretical anthropologic frame. Rappold describes his paintings as an autogamous play. For him, the act of drawing becomes a physical testing of boundaries. His paintings are large-scale, ostensibly figurative and abstract. More than three thousand years of art history and present-day artistic codes can be discerned as references in his art. The uniqueness of his work is caused by his artistic desires, aspirations, frustrations and aversions. His very personal approach to experimental and emotional art is remarkable. His paintings can be seen as a process of applying colour on sheets and removing or scraping it off again. The painting surface is defined as an alluvial plain (Vesely and Wallner 2016). There is a point in the artistic process, in which he either completely destroys the artwork, or it will result in something interesting. Narration and linguistic analogies are something he tries to avoid in his art. In the exhibition, Artist's Waste, Wasted Artists, four photoceramics with the titles 'Pipe', 'Everett', 'Taner' and 'No Title' from 2015, are shown. The topic of these works is the staging, or performance within a picture. It was not clear, whether the works are no more than requisites, or if they will be finished artworks. In Rappold's view, the picture is always a fetish as well. It transports within itself something that is actually not there. This is also the basis for the photoceramics. Originally, they were used at cemeteries, especially in southern Europe, showing people who are dead. It can be seen as a game with time.

For Rappold, waste can be seen as a positive term within art; for example, in the sense of the upgrading of trash. Rappold is attracted by artworks which follow an alchemist process, where waste is more a material or a starting point rather than an end product. For his paintings he uses unprimed sheets which he buys at monastery flea markets. These sheets are often older than 100 years and were washed thousands of times, but when he puts colour on them, they fit perfectly his purpose. Interestingly, a material which does not have any value at a first sight is suited best for his works. In his opinion, the process of valorisation is organic and hard to define. The question creates a kind of fog, because the object itself is nebulous. He argues that it has something to do with apparent, undefinable aspects such as intuition and even more, attitude. But how can we really define an attitude which is said to be important for the valorisation of art? As Fred Myers points out in the introduction of The Empire of Things, conditions of 
transnationalism have created new and often contradictory cultural and economic values and meanings of objects, also of art objects. These conditions are used to construct social identity and communicate cultural differences between groups and individuals. Historical conceptualizations of art have tended to challenge the priority of simple rationalization and in the West, art has been situated as a category of redemptive value, distinct from money and discrete from other sociocultural values. For this reason, art has an autonomy from other spheres of social life, which Myers calls the supposed neutrality of its classification. The value of an art object is linked to other political and social values (Myers 2002: 5-9). Furthermore, the valorisation of art and material culture, especially in the western world has often been based on the objects transcendence of global processes involving commodification, markets, money and mass culture. The value possessed by objects is subject to slippage and therefore problematic. It must be sustained or reproduced and is always linked to structures of social action. Due to that, Myers distinguishes between the qualitative value which is produced in organizations of difference and quantitative value as a measure of relative price in transactions. Both of them underlie significant dynamics of social structures. It is perceived that the category of art posits a hierarchy of cultural value and constitutes an arena of cultural evaluation (Myers 2002: 30-34).

Moreover, it is often argued that art history with its role models and art historic codes is influential in these processes of valorisation. Concerning this, Rappold believes that there cannot be a direct, or primary connection with that, because otherwise every artwork referring to the academic mainstream would be a high priced product, which is not the case. Myers argues that art history plays a role in the valorisation, because the workings of art objects and exhibitions are dependent on art's historical construction as an autonomous sphere of cultural activity. It is a sphere distinguished by its separation from considerations of utility or rationality and it is formulated on the notion of an aesthetic experience constructed through the contemplation of objects as art objects. Therefore, modern art must have its own artistic codes and parameters for value production. These processes of modernity are linked to the formulation of art as an autonomous domain of value, which turns art into a category that is separated from the rational, utilitarian, everyday world, but at the same time also has the possibility of enriching this world. Modernization is a process of self-fashioning, of directed transformation that makes culture the object of its planning. Myers argues that the cultural hierarchy distinguishes between high culture and popular mass culture. In this process of modernization, the category of art came to stand against kitsch and the mass produced inauthentic (Myers 2002: 32). For this reason, it can be argued that high values are not compatible with mass culture, but are instead connected to feelings, such as uniqueness and high quality. And yet, Andy Warhol and the likes have achieved precisely the paradoxical.

Art thus enters into more than a single regime of value or value production. As Thomson points out in Rubbish Theory, value is never a fixed characteristic of things, but is changeable. Through a cultural alchemy some things move from being worthless to valuable. The value of an object is dynamic, rising and falling, depending on the context. It maps out a relationship between status, the possession of objects and the ability to discard objects (Thompson 1979, 2-7). Finally, this can be compared to what Bernhard Rappold calls attitude. 
Myers, Fred. 2002. The Empire of Things: Regimes of Value and Material Culture. School of American Research Press.

Thompson, Michael. 1979. Rubbish Theory, The Creation and Destruction of Value. Oxford University Press

Vesely, Michael and Wallner, Larissa. 2016. 'Painting as autogamous play, erosion and self-circumvention versus illustration', https://www.bernhardrappold.com/ $\underline{\text { home }}$ 